\title{
Study on the Characteristics of Events in the Aviation, Leisure and Tourism Industry -Gyeongnam Sacheon Air Show
}

\author{
Gwi-Baek Kim ${ }^{1}$ and Hwa-Yeol Choi ${ }^{2 *}$ \\ ${ }^{1}$ Professor, Dept. of Marine Leisure Tourism, Youngsan University, South Korea \\ ${ }^{2}$ Professor, Dept. of Aviation Service Management, Jeju International University, \\ South Korea \\ 1'demi100@ysu.ac.kr, 2*hwayeol@hanmail.net
}

\begin{abstract}
The study of aviation leisure sports includes research that reviewed ways to boost aviation sports, research that examined the movement and growth of aviation sports, and plans to develop sports tourism programs using aviation sports, but it can be seen that empirical case studies are relatively insufficient compared to other leisure sports areas. The purpose of this study is to study the characteristics of tourism events, visitor satisfaction, and revisit intentions of aviation leisure sports as a case of the 2019 Sacheon Air Show, which was held as a priori leisure aviation event in Korea. The analysis showed that the Gyeongnam Sacheon Air Show contributed to presenting the growth vision of the aviation leisure industry and the factors that satisfy visitors of aviation leisure and sports are 'expected effect' factors. At last, it is necessary to actively reflect the characteristics in establishing strategies at the marketing level.
\end{abstract}

Keywords: Aviation, Leisure, Tourism, Events, Air shows

\section{Introduction}

\subsection{Research background and purpose}

Aviation leisure and sports refers to leisure and sports performed in the sky, and it is a futuristic leisure sports that applies fluid mechanics to adjust the speed and direction using wind and air pressure to enjoy the high thrill [1]. In particular, in many forms of sports tourism, the attractiveness of air sports, which is not affected by the season and creates high added value, has a greater tourism resource value than any other sport [2].

Korea is a member of the Korea Aviation Promotion Association and the Korea Aviation Association, the Korea Gliding Association, the Korea Skydiving Association, the Korea Airline Association, the Korea Air Transport Association, the Korea Power Parity Association, the Korea Sourcing Association, and the Korea Women's Airline Association. And professional associations for each type of air sports, such as the Korea Model Aviation Association. Recently, air sports competitions hosted by Donghoin clubs and leisure sports events sponsored or sponsored by local governments have been held. In particular, the air show called "Gyeongnam Sacheon Aerospace Expo" held in Sacheon, Gyeongnam from 2005 to 2018 has been renamed as "Sacheon Air Show" from 2019. This event is an event to check

Article history:

Received (June 2, 2020), Review Result (July 5, 2020), Accepted (August 6, 2020) 
the current status of the domestic and foreign leisure aviation industry at a glance, and has prepared various events and programs such as cultural events, leisure aviation industry exhibition, experience program, education / camp, and air show. With the success of the aviation leisure sports event in Gyeongnam, Sacheon will also be held in 2020, and plans to invest more to revitalize the aviation leisure and aviation related industries.

The purpose of this study was to study the characteristics of tourist events and the satisfaction of visitors by air leisure sports with the case of the 2019 Sichuan Air Show, which was held as a transcendent leisure air event in Korea. Through this, a basic understanding of air leisure sports and air leisure sports The aim was to explore the possibility of tourism resources.

In order to achieve the purpose of this study, literature review and empirical study were conducted. The theoretical background of the research subject was set by collecting and organizing data on aviation leisure sports through literature research related to the research subject first, and secondly, the Sichuan Air Show customer survey was conducted from October 24 to 27, 2019. The collected data were analyzed using statistical programs.

\subsection{Research trend}

Sports tourism is a trip based on leisure activities, in which an individual is temporarily attracted to a physical activity, participating in sports, or watching sports and engaging in exercising [3]. In addition, it is defined as tourism activities that move away from home in order to participate in all competitive and non-competitive sports tourism activities by participating in or watching sports [4]. Leisure and sports events created by integrating sports and tourism provide participants with motivation to participate in movement, and the venue for the event is a natural environment, established facilities, transportation, services, and hospitality. It is developed through [5]. In addition, holding leisure and sports events is an important concern among countries in terms of tourism activation, and sports events are contributing to creating synergies not only in the region's tourism, but also across society such as politics, economy, and culture [6].

In addition, research has been conducted in the leisure and tourism fields in terms of leisure and sports tourism. The effect of tourism activation by attracting sporting events [7] and the satisfaction factors of visitors for revitalizing local sports tourism [8]. In particular, with the popularization of sports participation tourism, which was exclusive to certain classes, the need for research on attracting sports tourism events, the characteristics of tourism resources and the influence of leisure activities, and sustainable tourism development in the tourism sector is increasing [9].

However, it can be seen that empirical case studies are relatively insufficient in the aviation leisure field compared to other leisure sports fields. This study aims to conduct a study on tourism characteristics, visitor satisfaction, re-visit and word of mouth effects for aviation leisure events that are emerging as new leisure sports events with the holding of the 2019 Sacheon Air Show.

\section{Types and status of aviation leisure sports}

\subsection{Ultralight airplane}

For the purpose of limited use such as leisure sports, the ultra-light aircraft for a single passenger in the Article 14 of the Enforcement Regulations of the Aeronautics Act of the 
Power System, which is 60-80 horsepower as a vehicle with limited flight performance, has its own weight and fuel capacity of $150 \mathrm{~kg}$ and $19 \ell, 2$ seater is limited to $225 \mathrm{~kg}$ and $38 \ell$.

In January 2004, the Ministry of Land, Transport and Maritime Affairs (formerly Ministry of Construction and Transportation) designated the airspace for flying aircraft, and if it leaves the airspace, it is required to obtain prior permission from the Airspace Commission [1]. There are about 20 airfields for ultra-light aircraft, including the Eomseom airfield in Hwaseong-si, Gyeonggi-do, as well as the Incheon Songdo airfield and the Jecheon airfield.

\subsection{Skydiving}

It is an air sports that uses a parachute to jump after climbing to a high sky using an aircraft or a device to perform a planned movement while freely descending, and when a specified altitude is reached, the parachute is unfolded and landed safely on the ground. The skydiving speed maintains an average speed of $180 \mathrm{~km} / \mathrm{h}$ in the basic attitude when free descending. The maximum speed can be up to $300 \mathrm{~km}$ depending on the posture, but it depends on the parachute type, adjustment method, wind direction and wind speed.

\subsection{Hang gliding}

It is a gliding sport that uses only human arm and leg strength and lands without using artificial power. It began to be distributed in Korea in the mid of 1970s, and hang gliders consist of a frame made of a special aluminum alloy pipe and a triangular frame attached to a body made of a nylon cloth called Dacron on top, weighing 20-30 kg. It is a weight that can be carried.

\subsection{Paragliding}

Refers to a vehicle assembled with a parachute and hang-gliding. The aircraft is laid out on a hill in advance, and it is connected to the aircraft by wearing a harness, a device that connects the body and the body, and then take off by running about $10 \mathrm{~m}$ downhill while receiving the wind. Power paragliding refers to paragliding that can take off even on the flat surface by attaching a small engine with a diameter of about $1 \mathrm{~m}$ to the paragliding, and is conducted in 10 active factories including Nakdong Riverside in Andong-si, Gyeongbuk and Namhan Riverside in Yeoju.

\subsection{Sports kite}

It is a leisure sport that blows objects made from triangles, squares, and various animal shapes in the sky. Linked to water leisure and sports such as Kite Buggy using a carriage wagon in the form of a wagon, Kite Ski running on snow or water, Kite Boat, and Kite Surf. Is developing.

\subsection{Model aircraft}

It is generally meant to be a non-human aircraft. It is defined as a model aircraft if its own weight is less than $25,000 \mathrm{~g}$ and engine volume is less than $250 \mathrm{~km}$. The history of domestic model aircraft began before the liberation and has the longest history compared to other aerospace sports fields, and the continuously active population is estimated to be around 10,000 nationwide [3].

\subsection{Hot air balloon}


It means that there is no propulsion device, such as a propeller or jet, among the mechanisms that obtain buoyancy by using a gas lighter than air. Brother Montgolfier in France in 1783 Brothers Montgolfier are brothers Joseph Michel Montgolfier (1740-1810) and brother Jacques Etienne Montgolfier (1745-1799).

Daejeon International Hot Air Balloon Festival has been held since 2005 with the theme of "Toward the Sky, to the World, to the Future" on the occasion of an international hot air balloon competition attended by 19 countries at Isidol Ranch in Jeju Island in April 1999.

\subsection{Drone}

As a dictionary definition, drones are collectively referred to as 'aircraft in the form of airplanes or helicopters in which humans fly through the induction of radio waves without riding.' The drone is an unmanned aerial vehicle and its historical departure worldwide was for the military industry. The early drones were developed for the military industry and operated primarily for reconnaissance and intelligence gathering. During this period, government agencies and large corporations mainly led drones to use them for military purposes. Early drones were very large in size, and their appearance was made like a miniature plane. However, drones have recently come into contact with various sizes and shapes and ideas, and are gradually expanding the scope of their applications to the civil and commercial fields [10].

\section{Sichuan air show}

\subsection{Background and significance of the Sichuan air show}

The aviation leisure event held in 2005, under the name of "Gyeongnam Sacheon Space Aviation Expo", was held until 2018 with various programs every year. From 2019, it was renamed "Sacheon Air Show" and was held as "2019 Sichuan Air Show" (http: //airshow.sacheon.go.kr). The regional festival is aimed at revitalizing the local economy by marketing new images of regions created through festival events [11]. The 2019 Sichuan Air Show is also included in one area of regional festivals in a wide range, so it can revitalize the surrounding local economy including Gyeongnam Sacheon. This event contributed to presenting the growth vision of the aviation leisure industry, which has been spotlighted as a high value-added knowledge-based industry, and to foster it as a mecca for aviation, leisure, and tourism. During the event, many visitors visited, and there were various productioninducing effects, income-inducing effects, and added-value inducing effects.

\subsection{Airshow and ground display of aircraft and equipment}

Experience flight: HH-47 (1 vehicle, C-130 (1 vehicle, university aircraft (10 vehicles, light aircraft (10 vehicles, KT-1 simulator ( 2 vehicles) / 1,062 pilot flights.

Ground exhibition: F-15K, KF-16, F-4E, F-5E, KA-1, T-50, KT-1, C-130, CN-235, HH-32, armored vehicles, etc. And riding experience.

\subsection{Public relations experience hall}

Operation of various promotional programs related to Sacheon-si general public relations, Air Force PR, aerospace-related school, institution, and company public relations, and aerospace 


\section{Method}

The questionnaire used in this study was based on previous studies on satisfaction and behavioral intentions in the field of aviation leisure, sports and event tourism (Heung-Ryeol Kim, Seol-Min Yoon, 2006; Jae-Hyung Lee, 2003; Gye-Sung Ko and Ki-Yoon Kim, 2009). 31 items, including 20 items of satisfaction factors such as diversity of programs, prices, events, and expected effects, two items of intention to ask for revisit and recommendation, and nine items of general items including demographic characteristics of respondents. Contains. As for the questionnaire question format, the general characteristics of the respondents used the nominal scale, and the questions related to the satisfaction factor and behavioral intention of the viewers were on the Likert formula 5-point scale (1=not at all, $2=$ no, $3=$ just yes, $4=y e s, 5=$ Very so). The subjects of the study were conducted for the general public who participated in the 2019 International Leisure Aviation Fair. A total of 430 copies were collected using the self-writing method, but a total of 414 copies were used for empirical analysis, excluding 16 copies that could not be used as data due to unfaithful responses or missing part of the survey.

As a result of the analysis, it was found that the 'expected effect' factors such as contributing to revitalization of the aviation leisure tourism industry, contributing to tourism promotion in Gyeonggi Province, contributing to interest in leisure aviation, and contributing to the promotion of related companies have the greatest influence on the behavior intention of visitors. This confirms that aviation leisure and sports events can greatly contribute to vitalization of related industries and regions. In addition, factors such as'facilities and viewing convenience', which indicate the safety and comfort of facilities, such as toilets and rest areas, and 'information and price appropriateness' factors such as appropriate admission fees and ease of information consultation were also found to have an effect on the intention of visitor behavior. As a result, it can be interpreted that the higher the satisfaction level of the aviation leisure event visitors" "expected effect," "facilities and viewing convenience," and "appropriate information and price," the more positive the audience's behavioral intentions are.

\section{Conclusions}

First, the Gyeongnam Sacheon Air Show contributed to presenting the growth vision of the aviation leisure industry, and brought about significant production, income and added value induction effects. The International Leisure Aviation Fair consisted of various events including air shows, exhibitions and experience events, providing many tourist events for visitors.

Second, the factors that satisfy visitors of aviation leisure and sports are 'expected effect' factors, such as convenience facilities, safety of facilities, venue comfort, and convenience of viewing facilities and viewing convenience, contributing to industrial revitalization and tourism promotion in Gyeonggi-do, etc. Four factors were derived, including 'theme program' factors such as food plaza and exhibition hall, and 'appropriate information and price' factors such as appropriate admission fee, ease of information consultation, and provision of various events and programs. In particular, the 'expected effect' factor, which can greatly contribute to the vitalization of industry and regional tourism, was highlighted, and this result was a practical help in establishing Gyeongsangnam-do's plan to foster Gyeongsangnam-do as a mecca for aviation and leisure tourism through the Gyeongnam Sacheon Air Show. Can give.

Third, as a result of examining the effect of viewers' satisfaction factors on behavioral intentions such as revisiting and recommendation intention, the factors 'expected effect', 
'facilities and viewing convenience', and 'appropriate information and price' have a significant effect on behavioral intention. Has been shown to affect. Particularly, the 'expected effect', a part that can contribute to related industries in aviation leisure tourism events, has the greatest influence, suggesting that it is necessary to actively reflect these characteristics in establishing strategies at the marketing level.

\section{References}

[1] Choi, Hyu-jong, "Current status and development plan of Korea's aviation leisure sports industry," Korean Society of Aviation Management Autumn Conference, pp.345-360, (2009)

[2] Choi Jong-in and Kang Hoon, "Plan to develop sports tourism program using air sports (focused on Seosan and Taean areas, Korea Sports Research, vol.14, no.5, pp.1238-1252, (2003)

[3] Green B. C. and Chalip L., "Sport tourism as the celebration of subculture," Annals of Tourism Research, vol.25, pp.275-91, (1998)

[4] Lisa D, "An overview of sport tourism: Building towards a dimensional framework," Journal of Vacation Marketing, vol.4, no.1, pp.23-38, (1998)

[5] Higham J. E. S. and Hinch T. D., "Tourism, sport and seasons: the challenges and potential of overcoming seasonality in the sport and tourism sectors," Tourism Management, vol.23, no.2, pp.175-185, (2002)

[6] Getz D, "Trend, Strategies and Issue in Sport in Sport-event Tourism," Sport Marketing Quarterly, vol.7, no.2, pp.8-13, (1998)

[7] Kim Kyung-Hoon and Shin Seung-Ho, "The analysis on decision factors and priority for sport event attraction of local governments," The Korean Journal of Sports, vol.18, no.1, pp.199-213, (2020)

[8] Kim Min-Soo, Seo Won-Jae, and Han Seung-Jin, "Suggestions for promoting the regional sport tourism industry based on a swot analysis and case studies, Korean Society of Policy, vol.16, no.4, pp.149-164, (2018)

[9] Cho Jae-Gi, Shin Young-Kyun, and Son Myeong-Jun, "Cooperation model between universities and local governments for marine leisure sports tourism products II,” Korean Journal of Physical Education, vol.43, no.2, pp.351-372, (2004)

[10] Park Chan-min, "A study of critical issues of recreational drone use words," The Korean Association of Sports Law, vol.19, no.1, pp.39-58, (2016)

[11] Lee Hyuk-jin and Choi Hwae-yeol, "Understanding of the hampyeong butterfly festival tourism event," Journal of the Korean Society of Photography Geography, vol.17, no.2, pp.53-65, (2007) 